\title{
Unaffordable medical scheme contributions: A barrier to access to private health cover in South Africa
}

\author{
T. Fish* \\ Department of Interdisciplinary Health Sciences: Community Health, \\ University of Stellenbosch, Stellenbosch 7600, Republic of South Africa \\ tfish@sun.ac.za \\ S. Ramjee \\ Actuarial Science, School of Management Studies, \\ University of Cape Town, Private Bag X3, \\ Rondebosch 7701, Republic of South Africa \\ shivani ramjee@uct.ac.za
}

Received February 2007

\begin{abstract}
The purpose of the Medical Schemes Act, No. 131 of 1998 was inter alia to 'promote non-discriminatory access to privately funded health care'. A number of reforms were proposed as steps on a path to Social Health Insurance (SHI) with the ultimate goal of the reforms being to increase the number of people contributing to a private financing mechanism, thereby reducing the burden on the public sector.

The increase in health care costs over time has been the focal point of industry discussions regarding affordability. In recent years the industry has responded positively to the affordability challenge by developing new products aimed at the lower end of the market. With medical inflation as a significant challenge, this paper argues that in 2003 the cost of entry-level medical scheme options was largely unaffordable and that this state of affairs has not improved over time. The proportion of the population covered by medical schemes declined marginally during the time period under review (2003 - 2006), despite the regulatory environment.
\end{abstract}

The analysis, done from the perspective of a prospective medical scheme member, aims to identify the proportion of medical scheme options affordable to each of four 'benchmark' families.

*To whom all correspondence should be addressed.

\section{Introduction}

South Africa has a well organised and regulated formal private health insurance system, with contributions to private prepaid plans in 2003 comprising $77,7 \%$ of private expenditure on health (World Health Organisation, 2006: 179). The private health insurance market is divided into two classes of product: medical schemes (regulated by the Medical Schemes Act, No. 131 of 1998) and what is termed 'health insurance' (regulated by the Long- and Short-term Insurance Acts of 1998). The environment is dominated by medical schemes, with 'health insurance' premiums comprising less than $1,5 \%$ of private health expenditure (McLeod, 2005: 141). This paper focuses on the medical scheme component of private coverage.

According to figures published by the Council for Medical Schemes, the absolute number of people covered by registered medical schemes increased slightly from $6,71 \mathrm{~m}$ in
2002 (Council for Medical Schemes, 2003a: 44) to 6,84m in 2005 (Council for Medical Schemes, 2006: 47). The proportion of the population covered declined marginally from $14,76 \%$ to $14,59 \%$ during this period, despite regulatory changes aimed at facilitating greater access to medical schemes by members of the public and efforts by the medical schemes themselves. These estimates are based on the mid-year population estimates determined by Statistics South Africa (Statistics South Africa, 2002b: 2; 2005a: 1).

It is frequently stated that it is the escalation in medical scheme contributions that has resulted in private cover being unaffordable. At the Risk Equalisation International Review Panel Workshop, the Minister of Health (2004) stated that the '...costs in the private sector have been increasing more rapidly than the inflation rate. This escalation of costs has caused medical aid cover to be unaffordable to many people'. This paper will argue that, in addition to the annual 
increases in contributions impacting negatively on affordability, the lowest cost options available to potential members are themselves unaffordable. Social health insurance reforms have to date not impacted positively on this minimum cost of cover.

The analysis, done from the perspective of a prospective medical scheme member, aims to identify what proportion of medical scheme options was affordable to each of four 'benchmark' families, during the period 2003 to 2006 . In the context of this paper, affordability is considered in terms of the cost of medical scheme contributions relative to the individual income of members.

\section{Background}

After the first democratic elections in 1994, there was a major shift in government policy with a return to the principles of social solidarity in the financing of health care. The Medical Schemes Act came into effect in February 1999 and key regulations to the Act on 1 January 2000. The purpose of the Medical Schemes Act was inter alia to 'promote non-discriminatory access to privately funded health care' (Council for Medical Schemes, 2003b: 2) through mechanisms such as open enrolment, community rating (as opposed to risk-rating by age and state of health), and the re-introduction of a set of minimum benefits to be provided by all medical schemes.

These reforms are interim steps on a path to SHI and ultimately National Health Insurance. The remaining reforms required for SHI are risk-related cross-subsidies (in the form of a Risk Equalisation Fund), income related crosssubsidies and mandatory cover.

The ultimate goal of the SHI reforms in their entirety is to increase the number of people contributing to a financing mechanism, thereby reducing the burden on the public sector. An aspect of improved access which has not been directly addressed by the reforms to date is that of affordability.

Other changes to the environment that could have reasonably been expected to improve affordability include medicine pricing regulation aimed at improving the affordability of medicines and changes to the tax subsidy for medical scheme contributions. In the 2006/7 tax year, the tax subsidy for contributions moved from a two-thirds tax-free provision and was replaced by a monthly monetary cap that takes into account the number of beneficiaries covered by medical scheme membership. The stated intention of the tax reform was to encourage broader medical scheme coverage (National Treasury South Africa, 2005: 1).

\section{Access to and affordability of cover}

The Health Charter (Department of Health, 2005: 7) defines access as "having the capacity and means to obtain and use an affordable package of health care services in South Africa in a manner that is equitable". The nature of medical schemes facilitates access to private health care by allowing for pre-payment, risk pooling, risk cross subsidies and access to financial protection (LIMS Process, 2006: 17-18). Access to medical schemes, in turn, is influenced by amongst other things, the affordability of cover. The affordability of cover depends on the level of the contributions relative to member income, and is affected by the tax structure and by the extent to which employers subsidise contributions.

If the assumption is made that the extent of coverage fairly represents access to the private health insurance mechanism, then the marginal decline in coverage over time may indicate a decline in the level of access. Figures from the annual reports published by the Council for Medical Schemes indicate that the average size of the insured family (i.e. beneficiaries per principal member) declined from 2,53 in 2002 (Council for Medical Schemes, 2003b: 45) to 2,43 in 2005 (Council for Medical Schemes, 2006: 47). This does not necessarily reflect a decline in actual family size, but is rather related to the existence of partially covered households (LIMS Process, 2006: 53).

In a community rated environment without mandatory membership the young and healthy can be expected to opt out of the system (LIMS Process, 2006: 61). While the declining proportion of the population covered by medical schemes may indicate decreasing levels of affordability, there is also the possibility that some people who can afford membership, choose to self-insure. The extent of the link between affordability and the decision to self-insure is not clear.

The General Household Survey (GHS) conducted by Statistics South Africa provides data on medical scheme access on both an individual and household level. The extent of coverage (Statistics South Africa, 2006) varies according to the individual income of the head of the household (Figure 1).

Although household income may be a better measure of affordability (and hence access), the analysis in this paper is based on the individual income of the principal member as this is the basis upon which medical scheme contributions are calculated. The assumption is made that the head of the household (as defined in the GHS) is the principal member of the scheme. 


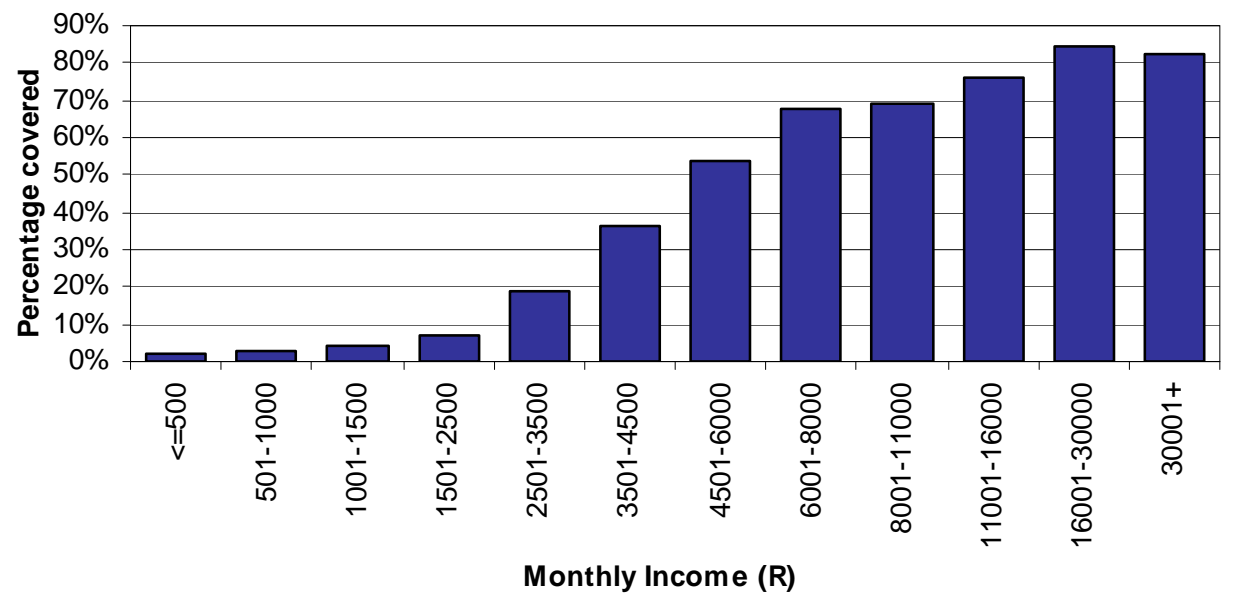

Figure 1: Comparison of the percentage of heads of household covered (by income group) in 2005

\section{Methodology}

The analysis was based on data for open membership schemes. By definition, restricted membership schemes are only accessible to new entrants to the medical scheme market who are employees of companies offering restricted scheme membership and not to the general public (as is the case for open membership schemes). Of the 50 open medical schemes registered in 2003, 48 were used in the sampling for this paper ${ }^{1}$. The schemes were stratified according to scheme size ${ }^{2}$ and administrator type (self- or third party administered) as these factors impact on scheme pricing. Scheme size was used as smaller risk pools are exposed to a higher level of variability in claims experience, and administrator type was used to allow for the effect of third party influence on scheme benefit design and operations.

25 percent of schemes in each stratum were sampled proportionately, based on the number of beneficiaries ${ }^{3}$ in each scheme in 2003. The 12 schemes in the sample (Table 1) represent $65.72 \%$ of beneficiaries in 2003 .

The analysis was based on the publicly available ${ }^{4}$ contribution tables of the schemes, for the years 2003 to 2006. Average contributions collected by schemes are influenced by family size and composition, and income levels of principal members. Therefore, to compare options from the perspective of a prospective medical scheme

${ }^{1}$ Of the two schemes omitted, one was liquidated and the other amalgamated with another scheme.

${ }^{2}$ Based on the definition of scheme size used by the Council for Medical Schemes.

${ }^{3}$ These data were obtained from the Council for Medical Schemes Annual Report 2004.

${ }^{4}$ Where possible, contributions tables were obtained from electronic brochures available from the scheme websites. Where contributions tables could not be obtained, scheme rules submitted to the Council for Medical Schemes were used. Data could not be reliably obtained for one of the schemes in the sample which was subsequently excluded. member, it was necessary to calculate the contributions for each of the options being compared without taking the profile of existing membership into account. Four benchmark families (based on family size and the income level of the principal member) were defined to enable the comparison of contribution levels across options and across time.

Initial work using a benchmark family (Ranchod, McLeod \& Adams, 2001) focused on a family consisting of a principal member, one adult dependant and two child dependants. This was based on data from the 1999 October GHS. An analysis of 2004 GHS data (Beheshty, 2006: 34) revealed that $19.22 \%$ of covered households with a working head of household had this structure. This was the second most common structure; the most common being the principal member only. The four benchmark families were therefore defined using the former family structure.

The four benchmark families were differentiated from each other by the income level of the principal member. This was necessary to measure the impact of the level of contributions on families with different levels of affordability. The four levels of income were labelled as 'very low', 'low', 'average' and 'high' (Table 3).

Table 1: Sampling framework

\begin{tabular}{l|l|c|c|c}
\hline $\begin{array}{c}\text { Scheme } \\
\text { size }\end{array}$ & $\begin{array}{c}\text { Administrator } \\
\text { type }\end{array}$ & $\begin{array}{c}\text { Number } \\
\text { of } \\
\text { schemes } \\
\mathbf{( 2 0 0 3 )}\end{array}$ & $\begin{array}{c}\text { Number } \\
\text { of } \\
\text { schemes } \\
\text { in } \\
\text { sample }\end{array}$ & $\begin{array}{c}\text { Number of } \\
\text { beneficiaries } \\
\text { in sample }\end{array}$ \\
\hline Large & Third party & 19 & 5 & $2,628,912$ \\
\hline Large & $\begin{array}{l}\text { Self- } \\
\text { administered }\end{array}$ & 6 & 2 & 358,196 \\
\hline Medium & Third party & 7 & 2 & 54,570 \\
\hline Medium & $\begin{array}{l}\text { Self } \\
\text { administered }\end{array}$ & 0 & 0 & - \\
\hline Small & Third party & 15 & 3 & 40,993 \\
\hline Small & $\begin{array}{l}\text { Self } \\
\text { administered }\end{array}$ & 1 & 0 & - \\
\hline Total & \multicolumn{2}{|c|}{48} & 12 & $3,082,671$ \\
\hline Source: Council for & & & & \\
\hline
\end{tabular}

Source: Council for Medical Schemes, 2004 
Each medical scheme may offer more than one benefit option. The number of benefit options offered by the sampled schemes varied from year to year (Table 2).

Table 2: Number of benefit options analysed

\begin{tabular}{c|c}
\hline Year & Number of benefit options \\
\hline 2003 & 63 \\
\hline 2004 & 74 \\
\hline 2005 & 81 \\
\hline 2006 & 74 \\
\hline
\end{tabular}

Source: Own data

Table 3: Income levels of benchmark families (in Rands)

\begin{tabular}{l|c|c|c|c|c}
\hline & $\begin{array}{c}\mathbf{2 0 0 1} \\
\text { terms }\end{array}$ & $\begin{array}{c}\mathbf{2 0 0 3} \\
\text { terms } \\
\text { (rounded } \\
\text { down) }\end{array}$ & $\begin{array}{c}\mathbf{2 0 0 4} \\
\text { terms } \\
\text { (rounded } \\
\text { down) }\end{array}$ & $\begin{array}{c}\mathbf{2 0 0 5} \\
\text { terms } \\
\text { (rounded } \\
\text { down) }\end{array}$ & $\begin{array}{c}\mathbf{2 0 0 6} \\
\text { terms } \\
\text { (rounded } \\
\text { down) }\end{array}$ \\
\hline $\begin{array}{l}\text { Very } \\
\text { Low }\end{array}$ & 1,700 & 2,000 & 2,210 & 2,400 & 2,500 \\
\hline Low & 2,000 & 3,200 & 3,530 & 3,840 & 4,010 \\
\hline Average & 4,667 & 5,700 & 6,300 & 6,850 & 7,160 \\
\hline High & 7,732 & 9,500 & 10,500 & 11,430 & 11,950 \\
\hline
\end{tabular}

Source: McLeod, personal communication, 2005, inflated using earnings statistics from Statistics South Africa ${ }^{5}$ (2003a; 2003b; 2004; 2005b; 2005c).

For each option in the sample the monthly contribution was calculated separately for each of the four benchmark families for the years 2003 to 2006 . The analysis was based upon an assumed employer contribution subsidy of $50 \%$. This assumption was based on the results of the Old Mutual Healthcare Survey (Old Mutual, 2005: 10) and the employer survey conducted as part of the Consultative Investigation into Low Income Medical Schemes (LIMS Process, 2006: 72), both of which found this to be the most common level of employer subsidy for working employees. The expenditure on private health care was defined as the monthly medical scheme contribution net of employer subsidy. This assumes that there is no other out-of-pocket expenditure on health care. In reality there may be benefits not covered by the scheme, co-payments or deductibles.

Accurate data regarding the proportion of income that principal members spend on medical scheme contributions are not available. The Income and Expenditure Survey (IES) provides data on the proportion of income spent by households on health care (including medical scheme contributions and out-of-pocket expenditure). Based on the IES conducted in 2000 (Statistics South Africa, 2002a) fully covered households (where all members of the household are covered by the medical scheme), spent on average $6.1 \%$ of their income on health care (Melzer, 2005: $45)$. However, the proportion of income spent on health care varied according to income, with lower income groups spending a higher proportion.

52001-2003: 23.61\%; 2003-2004: 10.55\%; 2004-2005: 8.87\%; 20052006: $4.55 \%$
Even though this figure includes out-of-pocket expenditure, the proportion of principal member income spent on medical scheme contributions during the study period was likely to be higher than $6.1 \%$ for the following reasons:

- Medical inflation exceeded consumer price inflation during the study period (Statistics South Africa, 2007)

- The principal member's income is at most equal to household income.

- The rand amounts provided in the IES for medical scheme contributions are lower than figures suggested by other industry sources.

Four levels of expenditure relative to income were tested, namely a monthly contribution of $5 \%, 10 \%, 15 \%$ or $20 \%$ of the principal member's income. A realistic level is likely to lie somewhere between $5 \%$ and $10 \%$. For the purposes of this paper the $10 \%$ level was used as a proxy for affordability.

\section{Results}

The results are illustrated in Figures 2,3 and 4. Figure 2 illustrates the proportion of options accessible to the various benchmark families based on the four levels of expenditure defined above. Results are presented for the 4-year period under review.

It is instructive to examine the distribution of the contributions for the available options. To do this the options are ranked by monthly contribution and split into quartiles (Figures 3 and 4). As contributions vary by income, this is done for each benchmark family and for comparative purposes the distributions are illustrated for the years 2003 and 2006. Each quartile is represented by the shading of the bars. The dashed line indicates the contribution payable if employees were to contribute $10 \%$ of their income and receive a $50 \%$ subsidy. The options above the dashed line can be considered affordable based on this definition, while those below the line can be considered unaffordable.

With an employee contribution of $5 \%$ of monthly income and an employer subsidy of $50 \%$, it is only the high income group that has access, albeit to a limited choice of options (between $4.05 \%$ and $9.88 \%$ of options) (Figure 2). For the very low income group, options only become accessible if employees contribute $20 \%$ of income and even then, only between $1.4 \%$ and $4.1 \%$ of options are accessible. At this high level of expenditure, there is a significant difference (at least 10-fold) in access between the very low and low income groups (Figure 3). The high income group is the only group where more than half of all options are accessible if at least $10 \%$ of income is spent on contributions. However, there are options that are not accessible even at the $20 \%$ level of income.

It is clear from Figures 3 and 4 that there has been almost no improvement in access at this $10 \%$ level. Access has only improved for the high income group, which may be due to a 
reduction in the use of income bands over time. The removal of income bands benefits high-income members of schemes as they no longer cross subsidise lower-income members.

The use of income bands to determine contributions does have some positive impact on access for the lower income families. In 2003 there were more options costing less than R 1100 for the 'very low' and 'low' income families as compared to the 'average' and 'high'. In 2006 there were no options costing less than R 1000 for the 'average' and 'high' income groups - i.e. access to lower cost options is restricted to those earning a lower income. Despite industry responses to a clear need for lower cost options, the absolute level of contributions remains at too high a level to facilitate access.

As expected, access to medical scheme coverage improves with increased income (Figure 2), but contrary to expectations there has been no clear improvement in access over time despite a regulatory framework which purports to improve access.

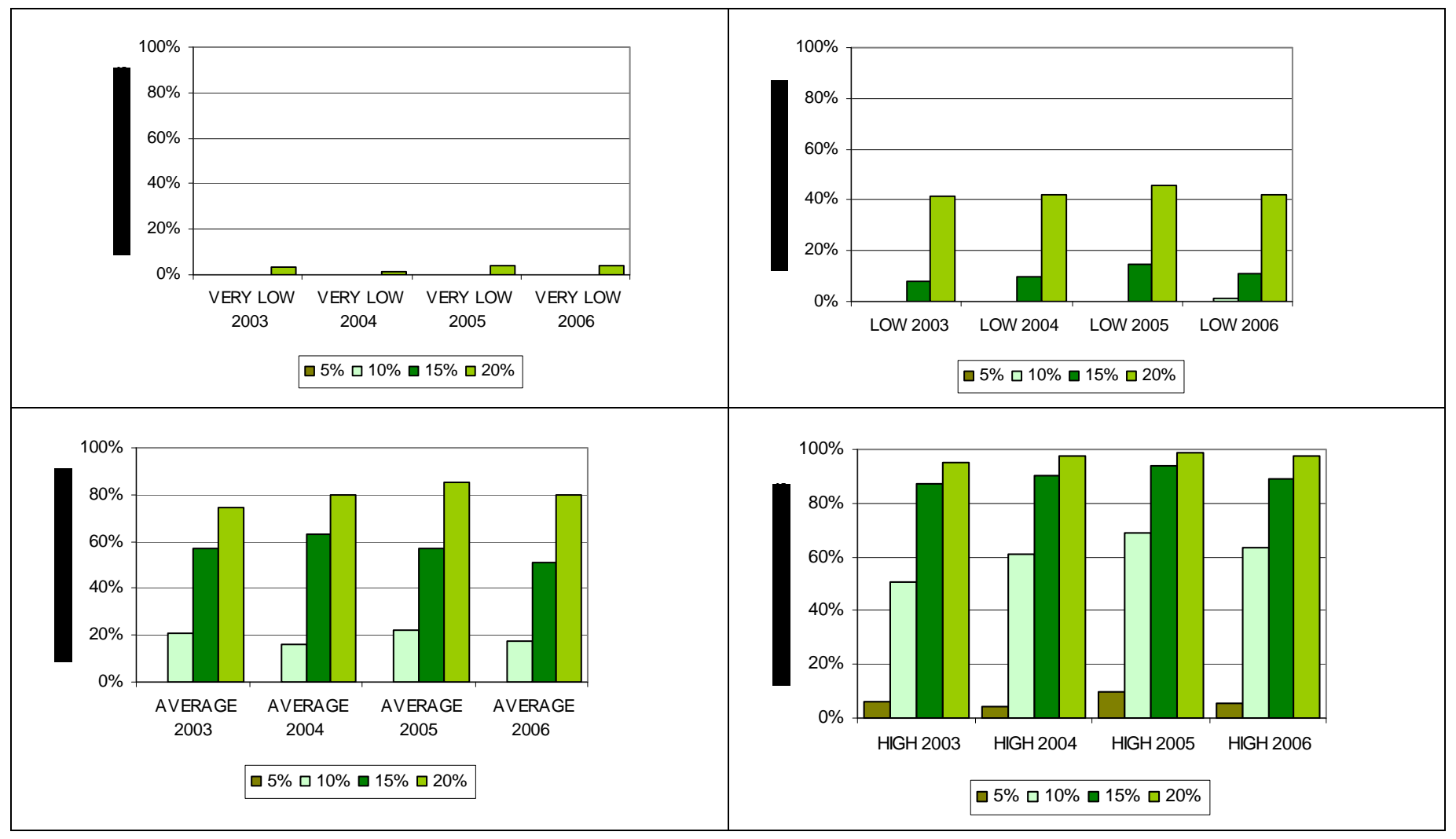

Figure 2: Proportions of options for the four benchmark families which are affordable over the four year period 


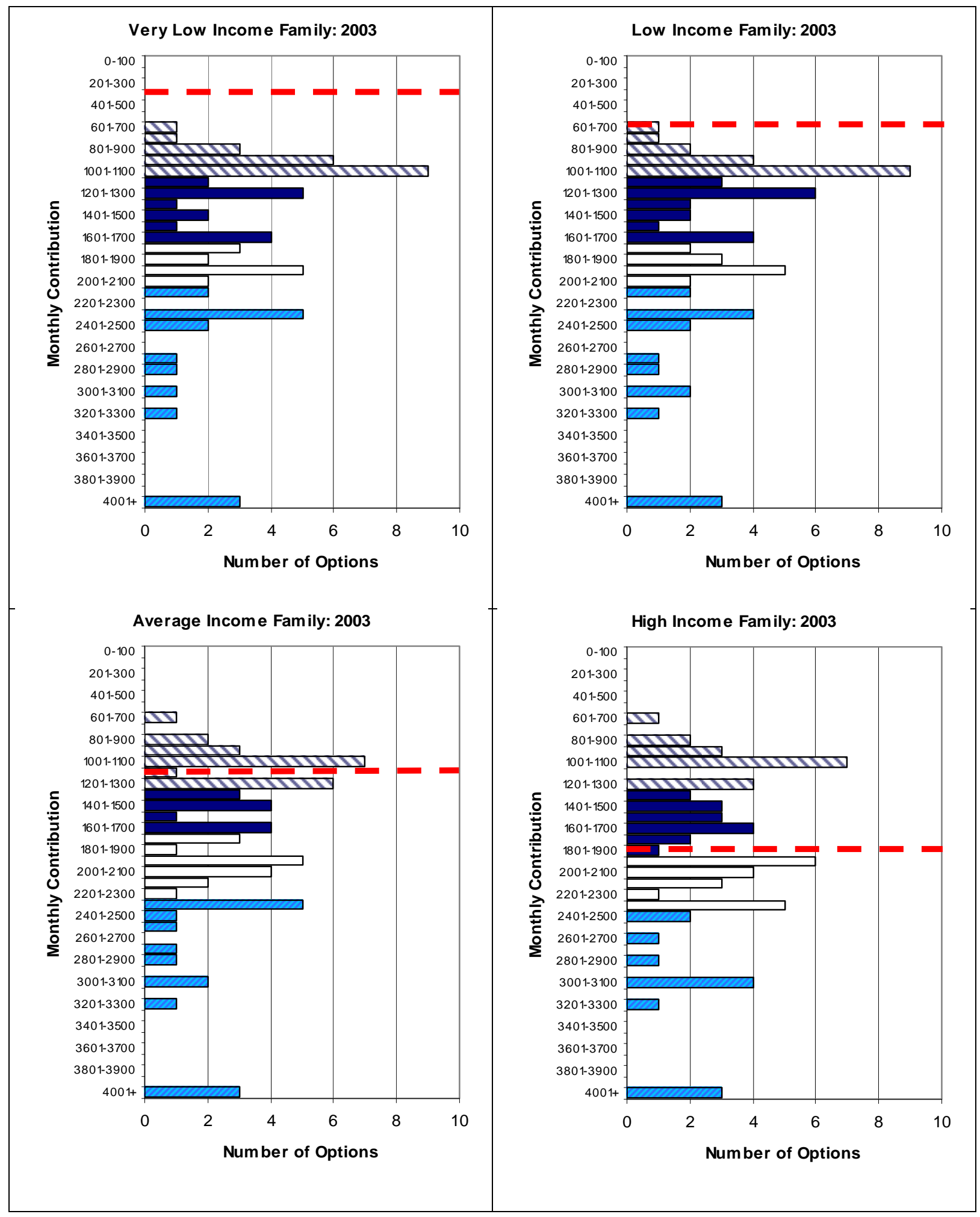

Figure 3: Distribution of contributions for the Benchmark Families: 2003 


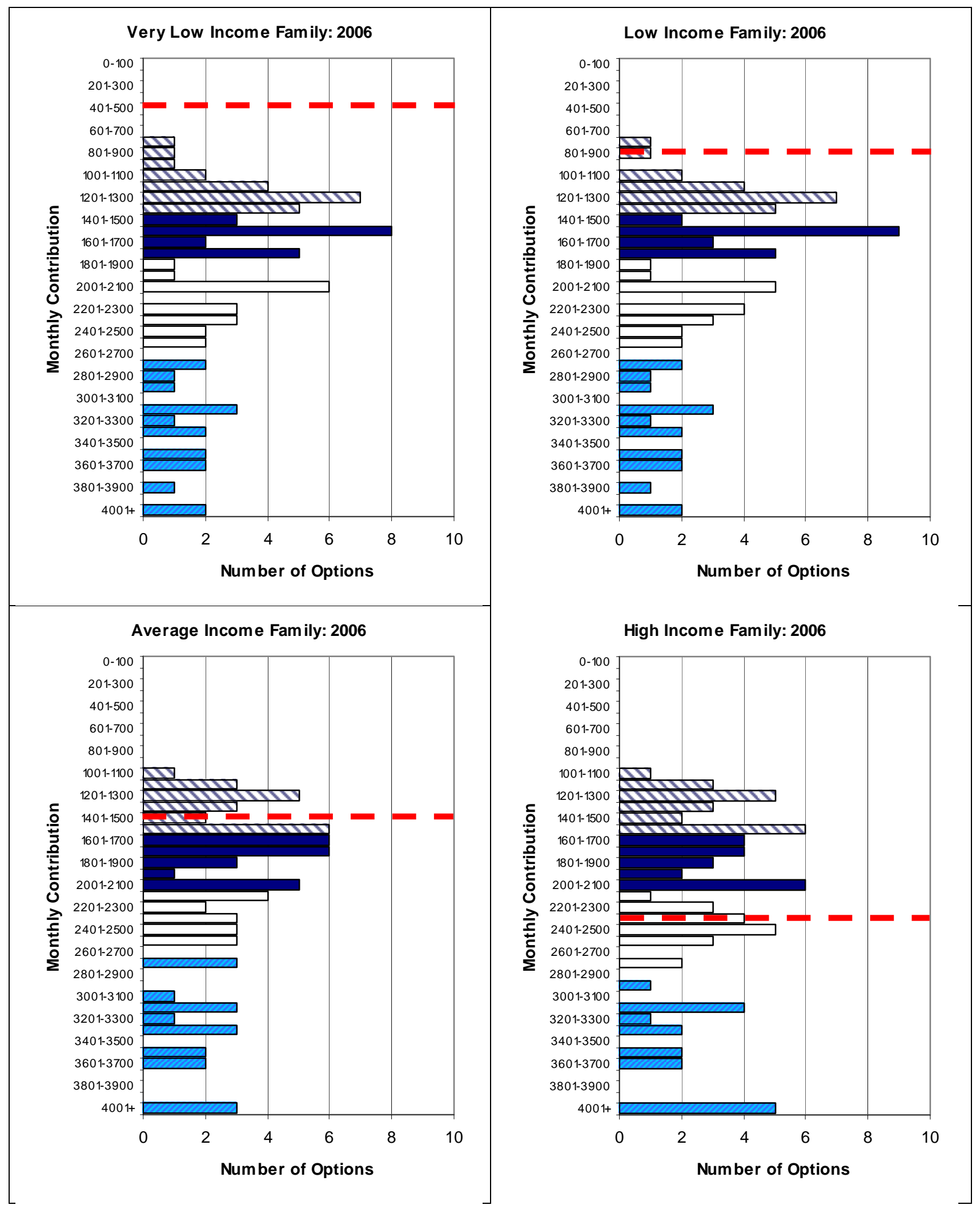

Figure 4: Distribution of contributions for the Benchmark Families: 2006 


\section{Conclusion}

The ultimate goal of the SHI reforms is to improve access to health care, and some of the changes to the regulatory environment that have been implemented to date have, had positive spin-offs. However, one of the unintended consequences of the reforms has been a failure to improve affordability and thereby to ensure access. This may be due to the significant delays between the various components of SHI being implemented and the absence of any income cross-subsidy component.

The negative impact has been greatest on lower income members of medical schemes, exacerbating the inequitable nature of the system. This increasing income inequity is referred to in the Health Charter: 'In the private sector membership of medical schemes has become increasingly unaffordable thus widening the gap between the highincome group and the middle-income group in terms of equitable access to health care' (Department of Health 2005: 39).

The increase in health care costs over time has been the focal point of industry discussions around affordability. While medical inflation is a significant challenge, the paper argues that in 2003 the cost of entry-level medical scheme options was largely unaffordable and this has not improved over time.

In recent years the industry has responded positively to the affordability challenge by developing new products aimed at the lower end of the market. The cost of entry-level products may be lower than historical product offerings in absolute terms. However, it is necessary to view the cost in relation to the proportion of income that can realistically be spent on health care. The methodology used in this paper illustrates that the majority of products available are still unaffordable. This has been recognised in the LIMS process which has advocated further regulatory change.

\section{Recommendations}

Mandatory contributions are an integral part of the envisioned SHI system. The current lack of affordability of entry-level products needs to be addressed in order to ensure the feasibility of mandatory contributions.

Considerable work still needs to be done within the South African setting to determine what the maximum proportion of income is that people are willing (and able) to spend on health care. It is likely that this proportion varies by income. The process of determining the price of an affordable package and then rationing benefits accordingly needs to be weighed against the need for an appropriate set of minimum benefits.

Affordability concerns are expected to be addressed through regulatory and structural changes such as those advocated by the LIMS process and income cross subsidies. In the interim, Industry needs to consider whether there is scope to reduce the cost of entry-level packages. This may be through the creative use of alternative delivery modes as well as through innovative benefit design.

Regardless of the changes made to the environment to improve access, a monitoring and evaluation process needs to be implemented. The methodology used in this paper could be applied at regular intervals.

Other areas of further research that would contribute to the debate and which were not included in this paper include the link between household and individual income, and the implications of recent tax reforms. The methodology suggested here can be further refined by taking into account alternative scenarios for employer subsidies, and the differences in benefit design between options. The methodology presented here does not consider working members and pensioners separately. In reality there are a number of factors that impact on affordability that affect these two groups separately (e.g. tax treatment and employer subsidies).

\section{References}

Beheshty, M. 2006. 'A definition of a low income benchmark family'. Unpublished Honours dissertation, Actuarial Science. Cape Town: University of Cape Town.

Council for Medical Schemes. 2003a. 'Annual Report 2002/2003'.

URL: http://www.medicalschemes.com. [online] 27 October 2005.

Council for Medical Schemes. 2003b. 'The medical schemes industry: Regulatory approach, trends, challenges \& opportunities', Portfolio Committee of Health. [online] URL: http://www.medicalschemes.com/.../Presentations $\% 2$ 0And\%20Reports/Portfolio\%20Committee\%2020\%20May \%202003.ppt. Accessed 27 October 2005.

Council for Medical Schemes. 2006. 'Annual Report 2005/2006'.

URL: http://www.medicalschemes.com. [online] 6 August 2006.

Accessed

Department of Health. 2005. The charter of the health sector of the Republic of South Africa'. Pretoria: Government Printer.

LIMS Process. 2006. 'Consultative investigation into low income medical schemes', Final report. [online] URL: http://www.medicalschemes.com. Accessed 17 November 2006.

Mcleod, H. 2005. 'Mutuality and solidarity in healthcare in South Africa', South African Actuarial Journal, 5: 135-167.

Meltzer, I. 2006. 'An overview of survey data relating to medical aid access, medical expenditure and utilisation. Consultative investigation into low income medical schemes'. Final LIMS Report 2006., Annexure 4. [online] URL: http://www.medicalschemes.com. 17 November 2006.
Accessed 
Minister of Health. 2004. 'Opening address at the Risk Equalization International Review Panel Workshop', Cape Town, 26 January.

National Treasury South Africa. 2005. 'Discussion document on the proposed tax reforms relating to medical scheme contributions and medical expenses', Pretoria: National Treasury.

Old Mutual. 2005. 'The Old Mutual 2005 Healthcare Survey'. Pinelands: Old Mutual.

Ranchod, S., Mcleod, H. \& Adams, S. 2001. 'Low-cost options in medical schemes. The need for low-cost options and an analysis of benefit designs used in 2001', Centre for Actuarial Research Monograph, Series, 6. Cape Town: University of Cape Town.

Statistics South Africa. 2002a. Income and expenditure of households 2000 South Africa. Pretoria: StatsSA. Statistical release $\mathrm{P} 0111$.

Statistics South Africa. 2002b. Mid-year estimates 2000, Pretoria: StatsSA. Statistical release P0302.

Statistics South Africa. 2003a. Labour statistics survey of average monthly earnings. Pretoria: StatsSA. Statistical release $\mathrm{P} 0272$.

Statistics South Africa. 2003b. Survey of employment and earnings. Pretoria: StatsSA. Statistical release P0275.

Statistics South Africa. 2004. Survey of employment and earnings. Pretoria: StatsSA. Statistical release P0275.

Statistics South Africa. 2005a. Mid-year estimates 2005. Pretoria: StatsSA. Statistical release P0302.

Statistics South Africa. 2005b. Quarterly employment statistics. Pretoria: StatsSA. Statistical release P02771.

Statistics South Africa. 2005c. Survey of employment and earnings. Pretoria: StatsSA. Statistical release P0275.

Statistics South Africa. 2006. General Household Survey 2005. Pretoria: StatsSA. Statistical release P0318.

Statistics South Africa. 2007. Consumer Price Index Time Series Data. Pretoria: StatsSA. Statistical release P0141.

World Health Organisations. 2006. World Health Report 2006. Annexure 2. Geneva: WHO. 
